Review

\title{
Asteraceae species with most prominent bioactivity and their potential applications: A review
}

\author{
Sílvia M.F. Bessada, João C.M. Barreira*, M.Beatriz P.P. Oliveira \\ REQUIMTE, Departamento de Ciências Químicas, Faculdade de Farmácia, Universidade do Porto, Rua Jorge Viterbo Ferreira, no 228, 4050-313, Portugal
}

\section{A R T I C L E I N F O}

\section{Article history:}

Received 28 April 2015

Received in revised form 24 July 2015

Accepted 28 July 2015

Available online 7 August 2015

\section{Keywords:}

Antioxidant and therapeutic activity

Bioactive compounds

Food

Medicinal and pharmaceutical uses

Secondary metabolites

\begin{abstract}
A B S T R A C T
Oxidative stress has a relevant part in the etiology of several diseases and metabolic disorders, being reasonable to expect that antioxidant compounds might have beneficial effects in health maintenance or disease prevention. Antioxidant compounds might be isolated and characterized from different plant constituents, such as roots, stems, bark, leaves, flowers, fruits and seeds, using proper extraction methods. The Asteraceae family has a worldwide distribution, with special relevance in the Mediterranean, Eastern Europe and Asia Minor, being acknowledged about 25000 species integrated in approximately 1000 genera. In addition to the anti-inflammatory, analgesic and antipyretic potential of some of these species, their high antioxidant power, as proven in research works with extracts (of roots, stems, bark, leaves, flowers, fruits and seeds) should be highlighted. Herein, the Asteraceae species with highest potential as sources of natural antioxidants with potential uses in medicine and in pharmaceutical, cosmetic and food industries were identified. The species were selected based on their botanical representativeness, being identified the 9 most relevant species: Achillea millefolium L., Acmella oleraceae Murr., Artemisia absinthium L., Bidens pilosa L., Carthamus tinctorius L., Inula crithmoides L., Matricaria recutita L., Otanthus maritimus L. and Parthenium hysterophorus L.. With the obtained information, it could be concluded that the bioactivity of the selected Asteraceae species lacks a complete characterization, constituting a research scope with great potential to be exploited in the development of dietary supplements, bioactive food ingredients or pharmaceutical based products with application in food industry, dermocosmetics or medicine.
\end{abstract}

(C) 2015 Elsevier B.V. All rights reserved.

\section{Contents}

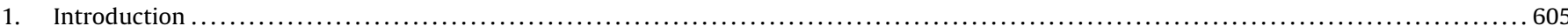

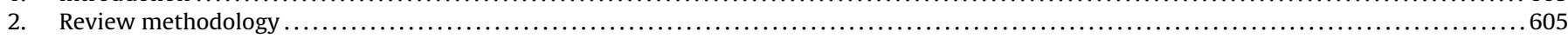

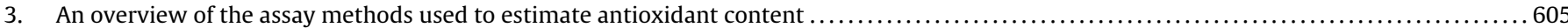

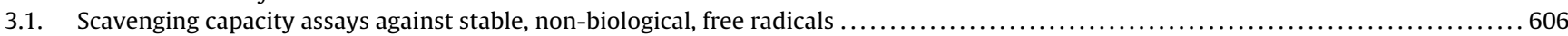

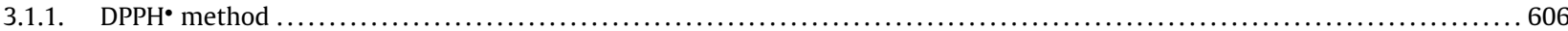

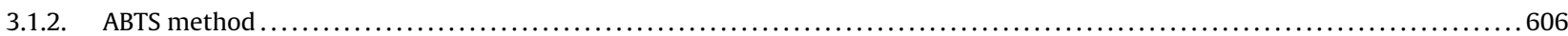

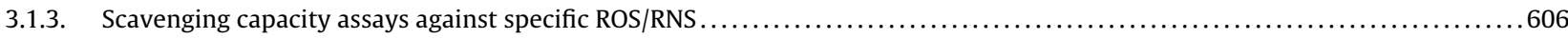

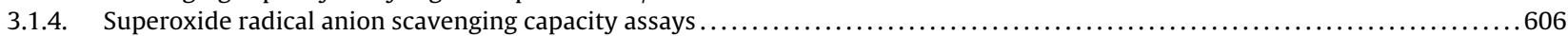

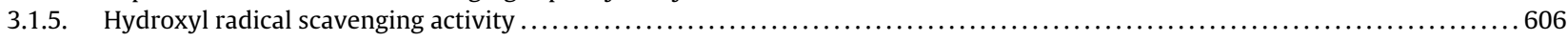

Abbreviations: AAPH,2,2', -azobis(2-methylpropionamidine) dihydrochloride; ABTS, [2,2'-azinobis(3-ethylbenzthiazoline-6-sulphonic acid)]; AUC, area-under-the-curve;

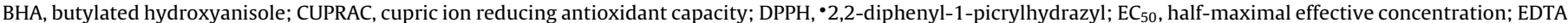

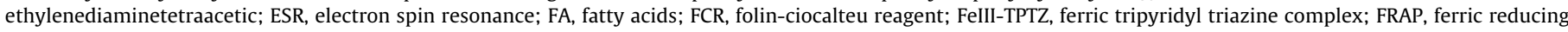

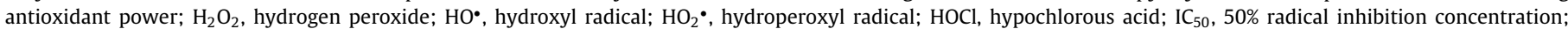

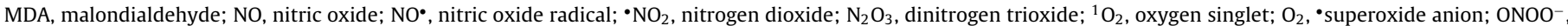

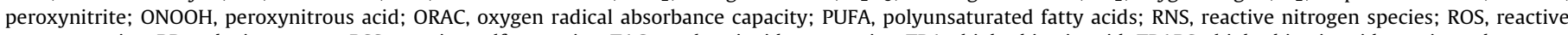

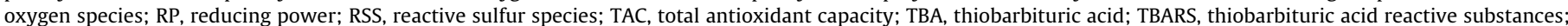
TPTZ, 2,4,6-tri-(2-pyridyl)-1,3,5-triazine; TRAP, total radical trapping antioxidant parameter.

* Corresponding author at: CIMO-ESA, Instituto Politécnico de Bragança, Campus de Santa Apolónia, Apartado 1172, $5301-855$ Bragança, Portugal. Fax: +351 273325405.

E-mail address: jbarreira@ipb.pt (J.C.M. Barreira). 


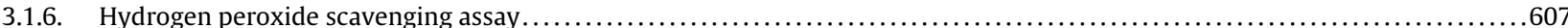

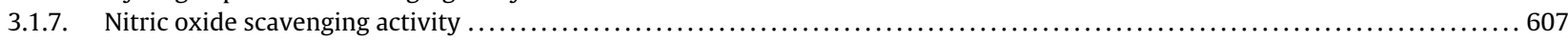

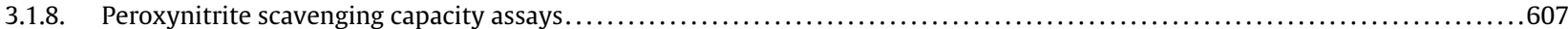

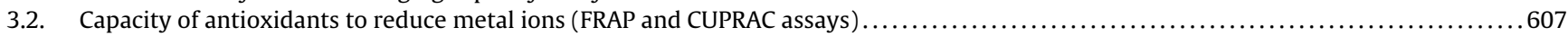

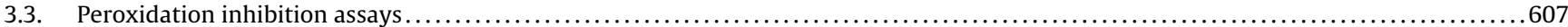

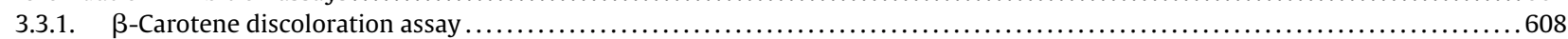

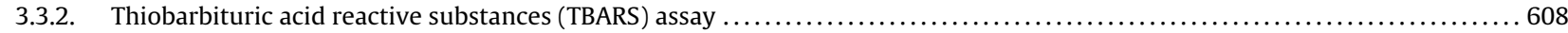

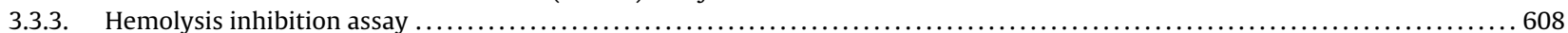

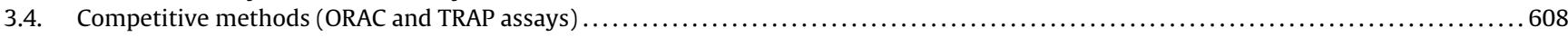

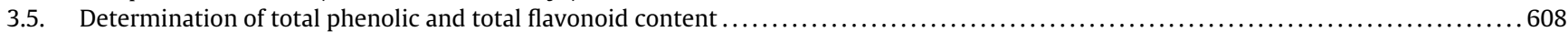

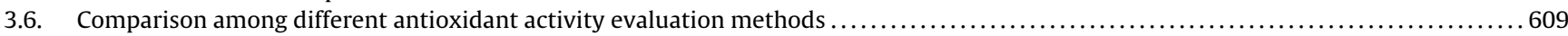

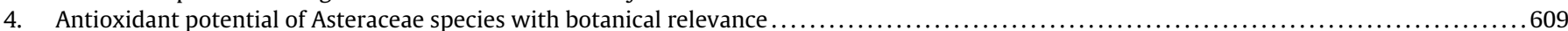

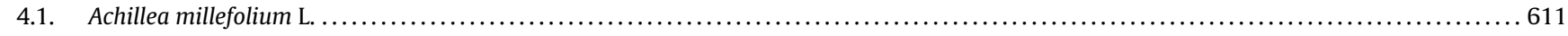

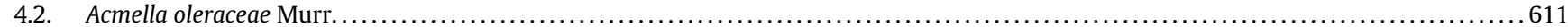

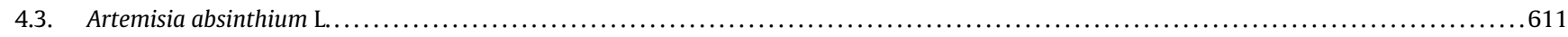

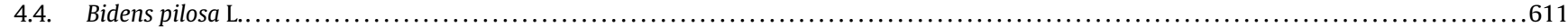

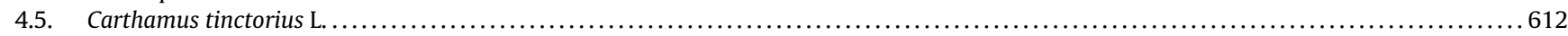

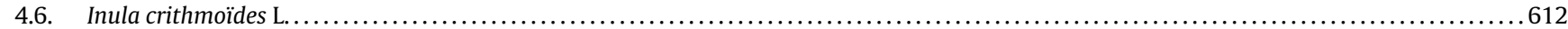

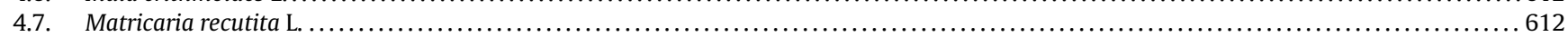

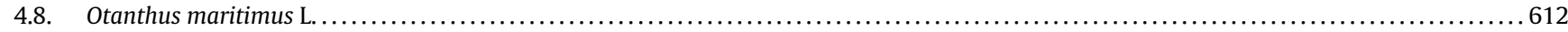

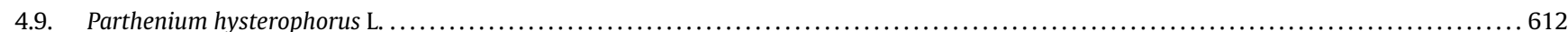

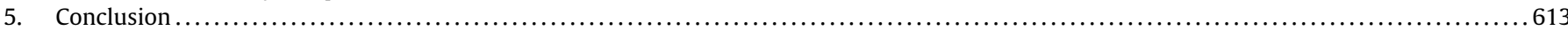

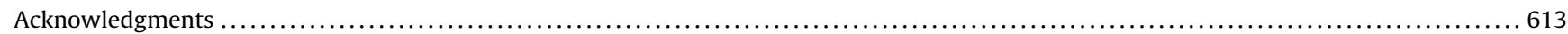

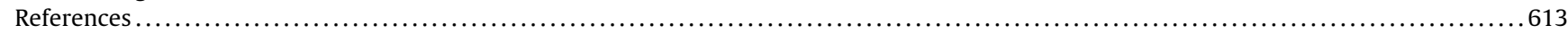

\section{Introduction}

In recent research, the central role of oxidative stress in the development of different pathophysiological conditions has been widely discussed (Flora, 2009; López-Alarcón and Denicola, 2013). Under stress, the human body produces more reactive oxygen and nitrogen species (ROS/RNS) than enzymatic antioxidants and non-enzymatic antioxidants, which might lead to cell damage and several health problems (Carocho and Ferreira, 2013; Krishnaiah et al., 2011). This physiological imbalance (oxidative stress) is a key factor in the onset of several pathologies like neurodegenerative (e.g., Alzheimer's disease) and cardiovascular diseases, inflammatory diseases, some cancers and even aging (Dasari et al., 2013; Jayasena et al., 2013; Ravishankar et al., 2013).

In fact, oxidative stress is a highly complex process and its physiological impact depends on different factors, such as the type of oxidant agent, the location and intensity of its production, the composition and roles antioxidant compounds, or the effectiveness of repair systems (Ďuračková, 2010). Under determined pathological conditions, the endogenous antioxidant defenses are not sufficient to balance the increased levels of cellular oxidative species (Benfeito et al., 2013). Accordingly, the administration of exogenous antioxidants might improve of oxidative status, due their double activity in compensating the inefficacy of the endogenous defense systems and in the enhancement of the overall antioxidant response (Berger et al., 2012; Bouayed and Bohn, 2010). Hence, antioxidants may prevent different oxidative damage pathways, yielding a useful therapeutic effect. Thereby, exogenous antioxidants uptake from diet will have essential functions in redox cell homeostasis, modulating cell functions and acting in the prevention of associated diseases (Bagh et al., 2011). Hence, a diet rich in antioxidants compounds, naturally present in plant sources, would be beneficial to human health. In this context, natural antioxidants represent a major field of research, either in the optimization of experimental techniques, as in their identification and characterization (Krishnaiah et al., 2011; López-Alarcón and Denicola, 2013).

The Asteraceae family includes a high number of flowering plants, grouped in nearly 1600 genera that gather over 23,000 species. Some of these species, such as chamomile (Matricaria recutita L.), yarrow (Achillea millefolium L.), or wormwood (Artemisia absinthium L.), are highly aromatic and were previously reported as having medicinal applications (Cabral et al., 2013; Kenny et al., 2014).

The purpose of this review is surveying the antioxidant capacity from diverse species of the Asteraceae family, as evidence of their interest and applicability as sources of natural antioxidants with potential medicine and pharmaceutical applications, or to be used in cosmetic and food industries. Thus, attention has been dedicated to the antioxidant capacity of natural products, emphasizing those frequently or potentially consumed by people, as well as their botanical representativeness in the Portuguese territory.

\section{Review methodology}

Relevant literature was collected by screening the major scientific databases, including SciFinder, Sciencedirect, Medline and Google Scholar. Since these databases are updated routinely, we are aware that the revised data is just indicative of the information available during the preparation of this paper. Among the screened publications, relevant references were selected considering (i) the reported in vitro and in vivo bioactivity evaluation assays and structural elucidation of bioactive compounds isolated from this family; (ii) species identification and information regarding the collection conditions.

\section{An overview of the assay methods used to estimate antioxidant content}

The advantageous role of antioxidants against several disorders and diseases derived from oxidative stress has been extensively studied, particularly their functions in the defense network in vivo. Phenolic compounds (e.g., phenolic acids and flavonoids), for instance, present anti-inflammatory, anti-carcinogenic, or antiatherosclerotic activities (among other biological effects), as result of their antioxidant activity (Krishnaiah et al., 2011; Niki, 2010).

The evaluation of antioxidant activity and the identification of specific antioxidant compounds can be performed through different assays designed for specific targets within the matrix. However, there is not a best universal method by which antioxidant capacity 
can be assessed accurately, providing unequivocal results. In fact, several methods were developed and applied in different systems, but sometimes the produced results are inconsistent, advising the utilization of various methods instead of a single dimension approach (Carocho and Ferreira, 2013; Niki, 2010).

Some of the methods used to investigate the antioxidant property of samples (diets, plant extracts, commercial antioxidants etc.) are based on synthetic antioxidants or free radicals, while others need animal or plant cells. These methods might have a broad scope of application or being specifically designed to evaluate a particular target, such as in the case of lipid peroxidation inhibition evaluation. The required knowledge and technical skills also differ among methods. Basically, these assays differ from each other in terms of reagents, substrates, experimental conditions, reaction media and analytical evaluation methods (Alam et al., 2013; Panda, 2012).

Considering the most recent studies (Alam et al., 2013; Niki, 2010; Panda, 2012), the most commonly in vitro methods used for the determination of antioxidant capacity are reviewed. The assays are based on different mechanisms, aiming to evaluate: (i) the depletion of free radicals by antioxidants: scavenging capacity assays against stable, non-biological, free radicals or against specific reactive oxygen species (ROS)/reactive nitrogen species (RNS); (ii) the capacity of antioxidants to reduce metal ions: ferric reducing antioxidant power (FRAP) and cupric ion reducing antioxidant capacity (CUPRAC); (iii) competitive methods: oxygen radical absorbance capacity (ORAC) and total radical trapping antioxidant parameter (TRAP); (iv) determination of total phenolic and total flavonoid content; (v) reducing power (RP).

\subsection{Scavenging capacity assays against stable, non-biological, free radicals}

Among free radical scavenging methods, 2,2-diphenyl-1picrylhydrazyl $\left(\mathrm{DPPH}^{\bullet}\right)$ method is more rapid, simple (i.e., not involved with many steps and reagents) and inexpensive in comparison to other test models. On the other hand, 2,2'-azinobis(3ethylbenzthiazoline-6-sulphonic acid) (ABTS) decolorizing assay is applicable for both hydrophilic and lipophilic antioxidants (Alam et al., 2013; Panda, 2012).

\subsection{1. $\mathrm{DPPH} \mathrm{H}^{\bullet}$ method}

$\mathrm{DPPH}^{\bullet}$ is based on the principle that a hydrogen donor might be considered as an antioxidant. This widely used colorimetric assay uses the $\mathrm{DPPH}^{\bullet}$ stable free radical, which has a strong purple color that changes to yellow (reduced form) in the presence of antioxidants. $\mathrm{DPPH}^{\bullet}$ is soluble in organic solvents and presents a typical absorption band at $515 \mathrm{~nm}$. The antioxidant activity is measured by the decrease in absorption at $515-528 \mathrm{~nm}$, which results from being reduced by the antioxidant in solution. The protocols used to apply this method differ in the concentration of $\mathrm{DPPH}^{\bullet}$, incubation time, reaction solvent and $\mathrm{pH}$ of the reaction mixture. In general, the reaction mixture should be prepared using a ratio of $5 \mu$ l of test sample and $95 \mu \mathrm{l}$ of $\mathrm{DPPH}^{\bullet}(300 \mu \mathrm{M})$ in methanol (Chetan et al., 2012). The reaction for scavenging $\mathrm{DPPH}^{\bullet}$ radical is usually carried out at $37^{\circ} \mathrm{C}$ in dark for $30 \mathrm{~min}$ and the absorbance is recorded at $517 \mathrm{~nm}$. A large decrease in the absorbance at the endpoint of the reaction indicates strong free radical scavenging activity of the tested compound/extract (Alam et al., 2013; Krishnaiah et al., 2011; Moon and Shibamoto, 2009; Sharma and Bhat, 2009).

\subsubsection{ABTS method}

The ABTS assay is a colorimetric assay in which the ABTS radical suffers a color decrease in the presence of antioxidants. Usually the $\mathrm{ABTS}$ cation radical $\left(\mathrm{ABTS}^{\circ+}\right)$ is prepared in solution with potassium, and the mixture is further incubated at room temperature in the dark for $12 \mathrm{~h}$. The $\mathrm{ABTS}^{\circ+}$ is generated by the oxidation of ABTS with potassium persulfate, and its reduction by hydrogen-donating antioxidants is measured spectrophotometrically at $734 \mathrm{~nm}$. The resulting solution is often diluted with methanol to get an appropriate absorbance. Due to the solubility of $\mathrm{ABTS}^{\circ+}$ in aqueous and organic solvents, this decolorizing assay measures the total antioxidant capacity in lipophilic and hydrophilic substances. In the determination of the antioxidant activity, the effect of the antioxidant concentration and the period taken to inhibit the radical cation's absorption should be considered (Chetan et al., 2012; Krishnaiah et al., 2011; Moon and Shibamoto, 2009; Niki, 2010).

\subsubsection{Scavenging capacity assays against specific ROS/RNS}

Free radicals are atoms, molecules or ions with unpaired electrons, which are highly active in chemical reactions. In biological systems, the free radicals are often derived from oxygen, nitrogen and sulfur molecules (Fig. 1). These free radicals integrate groups of molecules called ROS, RNS and reactive sulfur species (RSS). ROS, for instance, include free radicals such as superoxide anion $\left(\mathrm{O}_{2}{ }^{-}\right)$, hydroperoxyl radical $\left(\mathrm{HO}_{2}\right)$, hydroxyl radical $(\mathrm{HO} \bullet)$, nitric oxide (NO), and other species such as hydrogen peroxide $\left(\mathrm{H}_{2} \mathrm{O}_{2}\right)$, oxygen singlet $\left({ }^{1} \mathrm{O}_{2}\right)$ and hypochlorous acid $(\mathrm{HOCl})$ (Carocho and Ferreira, 2013). RNS are produced in animals, derived from the reaction of NO with $\mathrm{O}_{2}{ }^{\bullet}$ to form peroxynitrite $\left(\mathrm{ONOO}^{-}\right)$. Additionally, $\mathrm{ONOO}^{-}$can react with other molecules to form additional types of RNS including nitrogen dioxide $\left.\bullet \mathrm{NO}_{2}\right)$ and dinitrogen trioxide $\left(\mathrm{N}_{2} \mathrm{O}_{3}\right)$ (Pacher et al., 2007). RSS, on the other side, are produced from thiols to form a disulfide that might be further oxidized to disulfide-S-monoxide or disulfide-S-dioxide. These intermediate molecules can react with a reduced thiol producing sulfenic or sulfinic acid (Giles et al., 2001).

\subsubsection{Superoxide radical anion scavenging capacity assays}

Although superoxide anion is a weak oxidant, it is the starting point for the production of powerful and dangerous hydroxyl radicals and singlet oxygen, both contributing to oxidative stress. The superoxide anion scavenging activity can be measured after its generation in Tris- $\mathrm{HCl}$ buffer, containing nitroblue tetrazolium (NBT), $0.5 \mathrm{ml} \mathrm{NADH} \mathrm{solution} \mathrm{and} \mathrm{the} \mathrm{target} \mathrm{sample.} \mathrm{The} \mathrm{reaction}$ is initiated through the addition of phenazine methosulfate (PMS) solution, and further incubation at $25^{\circ} \mathrm{C}$ for $5 \mathrm{~min}$ followed by measuring the absorbance at $560 \mathrm{~nm}$ (Magalhães et al., 2008; Meyer and Isaksen, 1995; Robak and Gryglewski, 1988).

\subsubsection{Hydroxyl radical scavenging activity}

Hydroxyl radical $\left(\mathrm{HO}^{\bullet}\right)$ is one of the most potent ROS species in biological systems, being particularly active against the polyunsaturated fatty acid moieties of cell membrane phospholipidic layer. One of the standard methodologies (Kunchandy and Rao, 1990) used to evaluate the scavenging ability of hydroxyl radicals consists of mixing the extract with 2-deoxy-D-ribose (in $\mathrm{KH}_{2} \mathrm{PO}_{4}$ $\mathrm{KOH}$ buffer), ethylenediaminetetraacetic acid (EDTA), $\mathrm{FeCl}_{3}, \mathrm{H}_{2} \mathrm{O}_{2}$ and ascorbic acid and further incubation $\left(37^{\circ} \mathrm{C}, 1 \mathrm{~h}\right)$. The reaction is continued through the addition of thiobarbituric acid and trichloroacetic acid, and subsequently incubated $\left(100^{\circ} \mathrm{C}, 20 \mathrm{~min}\right)$. After cooling, absorbance is measured at $532 \mathrm{~nm}$, against a blank sample. Considering the high reactivity of $\mathrm{HO}^{\bullet}$, almost all chemical species in biological systems can be regarded as an $\mathrm{HO}^{\bullet}$ scavenger. Actually, this activity is not performed by any specific molecule or enzyme, which might diminish the relevance of directly evaluating the scavenging of $\mathrm{HO}^{*}$, simply because very high concentrations of scavenger are required to compete with adjacent molecules in vivo or in the food matrices for any generated $\mathrm{HO}^{\bullet}$. Hence, it is more useful to quantify the capacity of potential antioxidants to scavenge the formation of its precursors and/or to capture free metal ions related to $\mathrm{HO}^{\bullet}$ formation. The scavenger compounds with this 


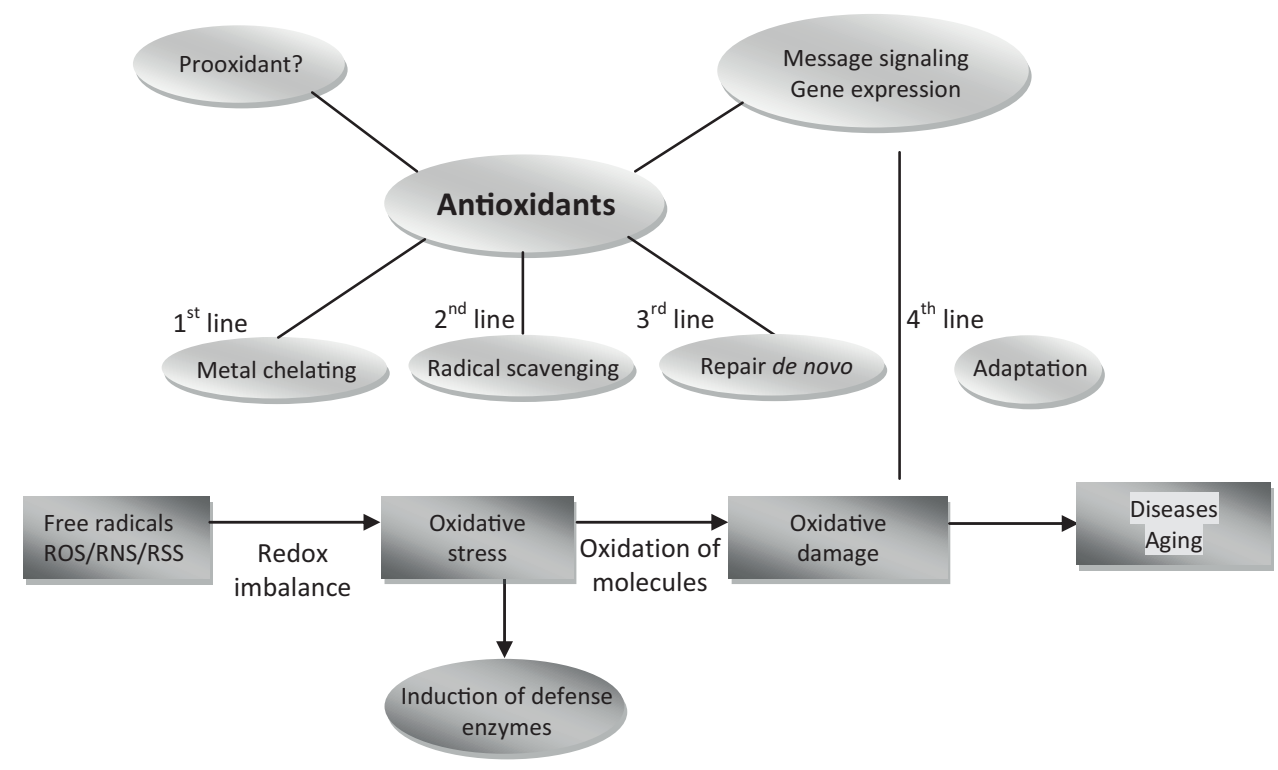

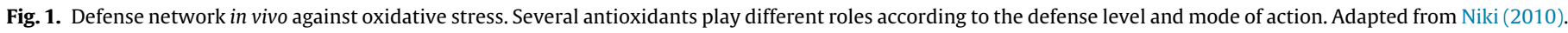

type of behavior would act as preventive antioxidants (Alam et al., 2013; Magalhães et al., 2008).

\subsubsection{Hydrogen peroxide scavenging assay}

Human beings are indirectly exposed to $\mathrm{H}_{2} \mathrm{O}_{2}$ via the environment (nearly $0.28 \mathrm{mg} \mathrm{kg}^{-1} \mathrm{day}^{-1}$ ) with intake mostly from leaf crops. $\mathrm{H}_{2} \mathrm{O}_{2}$ may enter into the human body through inhalation of vapor or mist and through eye or skin contact. It is promptly decomposed in oxygen and water, which might produce $\mathrm{HO}^{\bullet}$ that can initiate lipid peroxidation and cause DNA damage in the body. The ability of plant extracts to scavenge $\mathrm{H}_{2} \mathrm{O}_{2}$ is usually estimated using a buffered (phosphate buffer) solution of $\mathrm{H}_{2} \mathrm{O}_{2}$ in mixture with the extract and subsequent evaluation of the absorbance at 230 nm (Alam et al., 2013; Panda, 2012; Ruch et al., 1989).

\subsubsection{Nitric oxide scavenging activity}

Nitric oxide radical $\left(\mathrm{NO}^{\bullet}\right)$, acclaimed as the "molecule of the year" in 1992 by the Science Magazine (Koshland, 1992), has a key role in the modulation of diverse physiological processes. It is known that the nitric oxide generated from sodium nitroprusside in aqueous solution and physiological $\mathrm{pH}$ reacts with oxygen to produce nitrite ions, which can be quantified using the Griess reaction reagent, sodium nitroprusside (phosphate buffer), the target extract and a reference compound. A blank solution is also prepared with methanol and the solutions are incubated $\left(25^{\circ} \mathrm{C}\right.$, $60 \mathrm{~min})$, and further evaluated spectrophotometrically $(540 \mathrm{~nm})$. The inhibition of the generated nitrite oxide is quantified by comparing the absorbance values of control and test samples. Curcumin, caffeic acid, sodium nitrite, butylated hydroxyanisole (BHA), ascorbic acid and rutin are typically used as a positive control (Dasgupta and De, 2007; Magalhães et al., 2008; Panda, 2012).

\subsubsection{Peroxynitrite scavenging capacity assays}

Peroxynitrite $\left(\mathrm{ONOO}^{-}\right)$and peroxynitrous acid $(\mathrm{ONOOH})$ cause nitration or hydroxylation in aromatic compounds, particularly in tyrosine. Under physiologic conditions, peroxynitrite might also produce an adduct with the $\mathrm{CO}_{2}$ dissolved in body fluids. This adduct has been reported as inducing damages in proteins. Presently, the methods to measure $\mathrm{ONOO}^{-}$are the inhibition of tyrosine nitration and the inhibition of dihydrorhodamine-123 oxidation. The electron spin resonance (ESR) spectrometry assay is the only procedure able to detect specific free radicals involved in autoxidation processes (Antolovich et al., 2002; Huang et al., 2005).

\subsection{Capacity of antioxidants to reduce metal ions (FRAP and CUPRAC assays)}

These methods evaluate the capacity of samples to reduce ferric or cupric ions in aqueous media. The FRAP (ferric reducing antioxidant power) assay, originally developed to evaluate the ability of human plasma as antioxidant, is based on the reduction of the ferric iron in complex with 2,4,6-tri-(2-pyridyl)-1,3,5-triazine (Fe III-TPTZ) to the ferrous form at low $\mathrm{pH}$, measuring the ability of antioxidants as ferric iron reducing agents. FRAP values can be obtained by comparing absorption changes $(593 \mathrm{~nm})$ in the test mixture with those obtained from increasing concentrations of $\mathrm{Fe}$ III and expressed as mM of Fe II equivalents $\mathrm{kg}^{-1}$ (solid samples) or $\mathbf{1}^{-1}$ (liquid samples) of sample (Benzie and Strain, 1996, 1999; Panda, 2012).

CUPRAC method determines the potential of a sample to reduce the neocuproine-cupric complex (Nc-Cu II). In this case, the complex of Nc with the reduced form of the metal presents a characteristic absorption band with maximal intensity at $450 \mathrm{~nm}$. Thus, the capacity to reduce the metal complexes (generating the corresponding absorption bands) along a fixed incubation time allows determining FRAP or CUPRAC values. Nevertheless, while FRAP assay requires an acidic $\mathrm{pH}$ (3.6), that is far from the physiological $\mathrm{pH}$ value, CUPRAC assay is performed at $\mathrm{pH} 7.0$, simulating better the physiological conditions. In addition, CUPRAC assay differentiates the reducing power of thiol-type antioxidants (Apak et al., 2004; Güngör et al., 2011).

\subsection{Peroxidation inhibition assays}

Some lipid molecules, e.g., polyunsaturated fatty acids (PUFA), or their corresponding esterified forms, and cholesterol are vulnerable to free radicals attack. Lipid peroxidation induces changes in the biological membranes and produces potentially toxic compounds. As a starting point, the $\alpha, \beta$-unsaturated carbonylic compounds (e.g., 4-hydroxynonenal e acroleine) resulting from lipidic peroxidation, modify essential molecules such as proteins and DNA, which can trigger imbalances and disease. Antioxidants can slow this process in foods and biological systems (Blair, 2008). 
There are highly specific techniques available for the evaluation of oxidation in membranes, lipids present in food, lipoproteins and fatty acids (FA). The antioxidant effect on lipid peroxidation is measured by substrate loss, assays with peroxides or by determining final products (Niki, 2010). The lipid substrates that may be used include emulsions or liposomes produced from FA or their esterified forms. The biological systems might be erythrocytes or isolated lipoproteins (Antolovich et al., 2002).

\subsection{1. $\beta$-Carotene discoloration assay}

Carotenoids can be suffer discoloration by auto-oxidation induced by light, heat or ROO• (Karadag et al., 2009). $\beta$-carotene undergo rapid discoloration in the presence of a linoleate radical. During the oxidation, an $\mathrm{H}$ atom is removed from the active methylene bis-allyl group located in the $C_{11}$ position of linoleic acid, between two double bonds. The newly formed cyclopentadienyl radical attacks $\beta$-carotene unsaturated molecules to reacquire $\mathrm{H}$ atoms. When $\beta$-carotene molecules lose their conjugation, the orange color lost might be followed by spectrophotometry at $470 \mathrm{~nm}$ (Amarowicz et al., 2004; Burda and Oleszek, 2001). The kinetic approach allows the determination of complete inhibition effects and provides a more accurate assessment of the efficiency of antioxidant defenses, although the reactivity and antioxidant capacity cannot be determined separately (Karadag et al., 2009).

The addition of a sample containing antioxidant compounds or plant extracts has the ability to inhibit discoloration of $\beta$-carotene (Laguerre et al., 2007).

However, despite $\beta$-carotene is often used as a target compound, the discoloration may occur at $470 \mathrm{~nm}$ by different ways, which might difficult the interpretation of results (Prior et al., 2005).

\subsubsection{Thiobarbituric acid reactive substances (TBARS) assay}

TBARS assay is widely used for the detection of lipid oxidation. This method measures the malondialdehyde (MDA) formed from unsaturated FA cleavage upon oxidation of a lipid substrate. The formation of MDA from FA with less than three double bonds occurs through the secondary oxidation of primary carbonyl compounds (Fernández et al., 1997). MDA reacts with thiobarbituric acid (TBA), forming a pink pigment (TBARS) which is measured spectrophotometrically at $532 \mathrm{~nm}$ ( $\mathrm{Ng}$ et al., 2000). The procedure involves two distinct steps: the substrate is oxidized after addition of transition metal (such as iron or copper) ion, or a free radical; then the extent of the oxidation is defined by the addition of TBA and the spectrophotometric measurement of the product. The oxidation is inhibited by the addition of an antioxidant, whereby the decrease in absorbance can be measured. Results are typically quantified in terms of oxidation inhibition percentage (Antolovich et al., 2002).

\subsubsection{Hemolysis inhibition assay}

The erythrocytes are vulnerable to lipid peroxidation due to its high content of polyunsaturated lipids, the large supply of oxygen and the presence of transition metals (Zhu et al., 2002). When the erythrocytes are subjected to oxidative stress, free radicals lead to formation of hemolytic pores in the cell membrane. This injury results in a potassium leakage to the extracellular environment and consequent hemolysis (Bureau et al., 2005). Since lipid peroxidation is a chain reaction of free radicals, and considering that a free radical can induce up to twenty propagation reactions, the membrane of red blood cells is readily damaged. In the presence of antioxidant compounds, they react with the $\mathrm{ROO}^{\bullet}$ chain propagators, stopping peroxidation and thereby inhibiting hemolysis (Dai et al., 2006).

The azo compound 2,2'-azobis(2-methylpropionamidine) dihydrochloride (AAPH, sometimes also abbreviated as ABAP) can be decompose at physiological temperature to produce alkyl radicals, initiating lipid peroxidation. Once the AAPH is water-soluble and the rate of free radical generation can be controlled, it has been extensively used as free radicals initiator in biological studies (Dai et al., 2006; Niki et al., 1988).

The use of erythrocytes as a model systems has been applied extensively to study oxidative damage in biological membranes (Mabile et al., 2001), as the inhibition of hemolysis may be spectrophotometrically monitored at $540 \mathrm{~nm}$ (Ng et al., 2000).

\subsection{Competitive methods (ORAC and TRAP assays)}

These methodologies evaluate the ability to inhibit the depletion of a target molecule (usually monitored by UV-visible absorption or fluorescence spectroscopy) mediated by peroxyl radicals. Usually, AAPH is employed as peroxyl radical (ROO•) source, generating these radicals at a known rate in the first hours of incubation in aqueous media (López-Alarcón and Denicola, 2013).

The ORAC assay uses beta-phycoerythrin ( $\beta$-PE) or fluorescein as an oxidizable protein substrate (target molecule) and AAPH as a peroxyl radical generator or a $\mathrm{Cu}^{2+}-\mathrm{H}_{2} \mathrm{O}_{2}$ system as a hydroxyl radical generator. This assay is based in measuring the decrease in fluorescence in the presence of free radical scavengers (Trolox is a commonly used standard control). To date, it is the only method based in a complete free radical reaction that uses an area-underthe-curve (AUC) technique for quantification. This approach allows combining the inhibition percentage and the duration of inhibition of the free radical's action into a single quantity. The assay has been used in many recent studies of plants (Alam et al., 2013; Krishnaiah et al., 2011; Panda, 2012; Prior et al., 2003).

In recent years, TRAP is the most widely used in vivo method for measuring total antioxidant capacity of plasma or serum. This method uses peroxyl radicals generated from AAPH and peroxidizable materials present in plasma or other biological fluids. After adding AAPH to the plasma, the oxidation is monitored by measuring the oxygen consumed during the reaction. Throughout an induction period, this oxidation is inhibited by the antioxidants in the plasma. In this assay, the rate of peroxidation induced by AAPH is monitored through the decrease in the fluorescence of the protein $R$-phycoerythrin (R-PE) (Badarinath et al., 2010; Huang et al., 2005; Niki, 2010).

\subsection{Determination of total phenolic and total flavonoid content}

The amount of total phenolic content can be determined by Folin-Ciocalteu reagent (FCR) method. The exact chemical nature of the FCR is not known, but it is generally accepted that it contains complexes of fosfomolibdic/fosfotungstic acid. The chemical reaction is based on the electron transfer in alkaline conditions from phenolic compounds and other molybdenum reducing species, originating blue complexes that might be measured spectrophotometrically (Magalhães et al., 2008). The sample solution is mixed with the FCR (previously diluted) and allowed to stand (3 min, $25^{\circ} \mathrm{C}$ ) before a saturated sodium carbonate solution is added. The mixed solution is kept ( $120 \mathrm{~min}$ ) in the dark before the absorbance is measured ( $725 \mathrm{~nm}$ ). Gallic acid is used as a standard for the calibration curve and the total phenolics content is expressed as gallic acid equivalents (MacDonald-Wicks et al., 2006; Panda, 2012). Despite its wide use, the FCR method presents some limitations, such as the possibility of using different standards besides gallic acid, the fact that the final absorbance is proportional to the number of $\mathrm{HO}^{\bullet}$ groups (depending also on the molecule structure) and mainly because the reagent might be reduced by other compounds than phenolics (e.g., ascorbic acid, reducing sugars). Furthermore, it is limited to hydrophilic antioxidants. Usually, the identification and quantification of phenolic compounds should be achieved through chromatographic techniques in association with 
(1)<smiles>O=c1cc(-c2ccccc2)oc2ccccc12</smiles><smiles>O=C1C[C@H](c2ccccc2)Oc2ccccc21</smiles>

(3)

lar signaling pathways, mitochondrial interactions and changes in genetic expression (Hernandez-Montes et al., 2006).

Flavonoids are often determined following a colorimetric assay, in which the sample is mixed with a reagent containing aluminum chloride and sodium nitrite, producing a flavonoid-aluminum complex with a rosaceous color in alkaline medium (Zhishen et al., 1999). The aluminum cation forms stable complexes with flavonoids, causing a shift to higher wavelenghts (bathocromic). Phenolic acids, even those forming complexes with aluminium chloride, absorb in much lower wavelelenghts, thereby avoiding interferences in the obtained absorbances. Quercetin or catechin can be used as a positive control. The flavonoid content is usually expressed in terms of standard equivalent ( $\mathrm{mg} \mathrm{g}^{-1}$ of extracted compound) (Denni and Mammen, 2012; Ordoñez et al., 2006).

\subsection{Comparison among different antioxidant activity evaluation methods}

Any given antioxidant activity evaluation method should include an oxidation initiator, an adequate substrate and the exact definition of the reaction endpoint. Initiators might be an increase in temperature or in the partial pressure of oxygen, addition of metal catalyzers, exposure to light to promote photo-induced oxidation or shaking to promote contact among reagents (Karadag et al., 2009). The evaluation of the antioxidant activity in biological matrices in influenced by different factors such as antioxidants' partition coefficients among aqueous and lipidic phases, oxidation conditions and physical state of the oxidizable substrate (Frankel and Meyer, 2000). In conclusion, a standard antioxidant activity evaluation method should: (i) measure the potentially occurring chemical transformations; (ii) use a free radical source with biological relevance; (iii) achievable using simple technological methods; (iv) have a well-known reaction time and mechanism; (v) be attainable with equipment commonly available in the laboratory; (vi) have good reproducibility among assays; (vii) be adaptable to hydrophilic and lipophilic antioxidants; (viii) be applicable to different types of free radicals (Prior et al., 2005).

\section{Antioxidant potential of Asteraceae species with botanical relevance}

Some researchers propose that two-thirds of the world's plant species have medicinal value (Krishnaiah et al., 2011). This potential biological activity is often related to their great antioxidant capacity. Therefore, medicinal plants used in folk medicine are raising increasing interest for their potential application in pharmaceutical, food and nutraceutical fields. In addition, the so called phytomedicines are playing a progressively higher role in human health care system. Considering the social demands related to health and nutrition, medicinal plants emerge as a strong alternative to synthetic products, used both in traditional medicine and in food and pharmaceutical products, due to their nutritional properties and bioactivity. Due to their high range of application, it is useful to elucidate their mechanisms of action, in order to develop better medicinal products. Plants contain a high diversity of free radical scavenging molecules, such as phenolic compounds, nitrogen compounds, vitamins, terpenoids, among others (Chetan et al., 2012; Phillipson, 2007).

The Asteraceae family consists of approximately 1000 genera, which comprise over 25,000 species of flowering plants, some with wide uses for medicinal purposes, as in the case of chamomile (M. recutita L.), yarrow (A. millefolium L.), or wormwood (Artemisia absinthium L.). Different types of biological activities were previously reported in several Asteraceae species throughout the world (Table 1). Despite the relatively high number of studies reporting cal generation, flavonoids (especially isoflavones) might exert their effects via different mechanisms such as the modulation of cellu- 
Table 1

Bioactivity screening assays performed using Asteraceae species from different geographic locations.

\begin{tabular}{|c|c|c|c|}
\hline Species & Assays & Origin & Authors \\
\hline Achillea beibersteni & Phenols content; antioxidant activity & Saudi Arabia & Shahat et al. (2014) \\
\hline Achillea fragrantissima & Phenols content; antioxidant activity & Saudi Arabia & Shahat et al. (2014) \\
\hline \multirow[t]{9}{*}{ Achillea millefolium } & Anxiolytic activity & Brazil & Baretta et al. (2012) \\
\hline & Antimicrobial and antioxidant activitites & Turkey & Candan et al. (2003) \\
\hline & Vasoprotective activity & Italy & Dall'Acqua et al. (2011) \\
\hline & Phytochemicals, antioxidant and antitumor activities & Portugal & Dias et al. (2013) \\
\hline & Phenols content; antioxidant activity & Iran & Gharibi et al. (2013) \\
\hline & Antiulcerogenic and antioxidant activities & Brazil & Potrich et al. (2010) \\
\hline & Hypotensive effects & Brazil & Souza et al. (2011) \\
\hline & Phenolic compounds; antioxidant activity & Italy & Vitalini et al. (2011) \\
\hline & Antioxidant activity and modulation of mitochondria respiration & Lithuania & Trumbeckaite et al. (2011) \\
\hline Acmella oleraceae & Phytochemicals and antioxidant activity & Sri Lanka & Abeysiri et al. (2013) \\
\hline Ageratum conyzoides & Analgesic potential; antioxidant activity & Bangladesh & Dewan et al. (2013) \\
\hline Ageratum houstonianum & Antioxidant activity & India & Tennyson et al. (2012) \\
\hline Ambrosia artemisiifolia & Antioxidant activity & Serbia & Maksimović (2008) \\
\hline Anthemis deserti & Phenols content; antioxidant activity & Saudi Arabia & Shahat et al. (2014) \\
\hline Arctium minus & Antimicrobial and antioxidant activitites & Ireland & Kenny et al. (2014) \\
\hline \multirow[t]{9}{*}{ Artemisia absinthium } & Hepatoprotective activity & China & Amat et al. (2010) \\
\hline & Phytochemicals, antifungal and antiparasitic activities & Spain & Bailen et al. (2013) \\
\hline & Neuroprotective activity & India & Bora and Sharma (2010) \\
\hline & Antioxidant activity & Serbia & Canadanovic-Brunet et al. (2005) \\
\hline & Antifeedant, antiparasitic and antioxidant activities & Spain & Gonzalez-Coloma et al. (2012) \\
\hline & Phenolic compounds; antioxidant activity & Australia & Lee et al. (2013) \\
\hline & Anti-venom activity & Turkey & Nalbantsoy et al. (2013) \\
\hline & Antitumor activity & India & Shafi et al. (2012) \\
\hline & Anthelmintic activity & India & Tariq et al. (2009) \\
\hline Artemisia monosperma & Phenols content; antioxidant activity & Saudi Arabia & Shahat et al. (2014) \\
\hline \multirow[t]{9}{*}{ Bidens pilosa } & Antioxidant and immunomodulatory activities & Cuba & Abajo et al. (2004) \\
\hline & Antidiabetic activity & Taiwan & Chien et al. (2009) \\
\hline & Antioxidant and antimicrobial activities & Japan & Deba et al. (2008) \\
\hline & Anti-hypertensive activity & Cameroon & Dimo et al. (2002) \\
\hline & Anti-hyperglycemic activity & Taiwan & Hsu et al. (2009) \\
\hline & Antitumor activity & Brazil & Kviecinski et al. (2008) \\
\hline & Immunosuppressive and anti-inflammatory & Brazil & Pereira et al. (1999) \\
\hline & Antimalarial activity & Brazil & Oliveira et al. (2004) \\
\hline & Antioxidant activity & Taiwan & Yang et al. (2006) \\
\hline Carthamus tinctorius & Several biological activities & Several origins & Zhou et al. (2014) \\
\hline Centaurea nigra & Antimicrobial and antioxidant activitites & Ireland & Kenny et al. (2014) \\
\hline Centaurea paniculata & Phytochemicals; antioxidant activity & Portugal & Barros et al. (2010) \\
\hline Centaurea scabiosa & Antimicrobial and antioxidant activitites & Ireland & Kenny et al. (2014) \\
\hline Chicorium intybus & Antioxidant activity & Poland & Rozpądek et al. (2014) \\
\hline Cirsium arvense & Antimicrobial and antioxidant activitites & Ireland & Kenny et al. (2014) \\
\hline Cirsium palustre & Antimicrobial and antioxidant activitites & Ireland & Kenny et al. (2014) \\
\hline Cirsium vulgare & Antimicrobial and antioxidant activitites & Ireland & Kenny et al. (2014) \\
\hline Echinacea purpurea & Antimicrobial & Portugal & Martins et al. (2015) \\
\hline Eriocephalus spp. & Enzymatic inhibition; antioxidant activity & South-Africa & Njenga and Viljoen (2006) \\
\hline Helichrysum spp. & Antimicrobial and antioxidant activitites & Turkey & Albayrak et al. (2010) \\
\hline Helichrysum stoechas & Phytochemicals; antioxidant activity & Portugal & Barros et al. (2010) \\
\hline \multirow[t]{3}{*}{ Inula crithmoïdes } & Antioxidant, anticlastogenic and antimutagenic activities & Egypt & Abdel-Wahhab et al. (2008) \\
\hline & Antimicrobial and antioxidant activitites & Tunisia & Jallali et al. (2014) \\
\hline & Herbicidal activity & Tunisia & Omezzine et al. (2011) \\
\hline Lychnophora passerina & Flavonoids content; antioxidant activity & Brazil & Chicaro et al. (2004) \\
\hline \multirow[t]{8}{*}{ Matricaria recutita } & Phytochemicals; antioxidant activity & Portugal & Barros et al. (2010) \\
\hline & Neuroprotective activity & India & Chandrashekhar et al. (2010) \\
\hline & Anti-allergic activity & India & Chandrashekhar et al. (2011) \\
\hline & Phytochemicals, antioxidant activity, cytotoxicity & Portugal & Guimarães et al. (2013) \\
\hline & Antimicrobial activity & Iran & Jamalian et al. (2012) \\
\hline & Several biological activities & Several countries & McKay and Blumberg (2006) \\
\hline & Antioxidant activity & Portugal & Martins et al. (2015) \\
\hline & Antidiarrheal and antioxidant activities & Tunisia & Sebai et al. (2014) \\
\hline Mikania cordifolia & Analgesic potential; antioxidant activity & Bangladesh & Dewan et al. (2013) \\
\hline \multirow[t]{2}{*}{ Otanthus maritimus } & Antimicrobial and cytotoxicity activies & Portugal & Cabral et al. (2013) \\
\hline & Repellency agains insects & Greece & Tsoukatou et al. (2000) \\
\hline Parthenium & Cytotoxic activity & India & Das et al. (2007) \\
\hline \multirow{5}{*}{ hysterophorus } & Antioxidant activity & India & Krishnaveni (2013) \\
\hline & Antioxidant activity & India & Kumar et al. (2013) \\
\hline & Antibacterial, antioxidant, and cytotoxic activities & India & Kumar et al. (2014) \\
\hline & Antifungal activity & India & Rajiv et al. (2013) \\
\hline & Antioxidant activity & Pakistan & UdDin et al. (2015) \\
\hline Picris cyanocarpa & Phenols content; antioxidant activity & Saudi Arabia & Shahat et al. (2014) \\
\hline Pulicaria crispa & Phenols content; antioxidant activity & Saudi Arabia & Shahat et al. (2014) \\
\hline Rhantarium epapposum & Phenols content; antioxidant activity & Saudi Arabia & Shahat et al. (2014) \\
\hline Sonchus asper & Antimicrobial and antioxidant activitites & Ireland & Kenny et al. (2014) \\
\hline Taraxacum officinale & Antimicrobial and antioxidant activitites & Ireland & Kenny et al. (2014) \\
\hline Taraxacum sect. Ruderalia & Phenols content; antioxidant activity & Portugal & Dias et al. (2014) \\
\hline Vernonia spp. & Medicinal properties & Several countries & Toyang and Verpoorte (2013) \\
\hline
\end{tabular}


their biological potential, Portuguese species were scarcely investigated and the species with highest potential will be the primary focus of attention in the next section. Considering this subject, the present review is especially dedicated to the in vitro antioxidant properties of extracts from the stems, roots, bark, leaves, flowers, fruits and seeds of the Asteraceae species with botanical relevance in Portugal.

\subsection{Achillea millefolium $L$.}

A. millefolium L., commonly known as yarrow (milefólio or ervacarpinteira) is widespread in mountain meadows, pathways, crop fields and home gardens. Its infusion and alcoholic extracts are widely used to treat digestive problems, diabetes, hepato-biliary diseases and amenorrhea, being also consumed for its antitumor, antimicrobial, anti-inflammatory and antioxidant properties, among others. When consumed in the form of a decoction, it is mainly used for digestive and intestinal disorders, besides being externally used for skin and mucosa inflammations (Baretta et al., 2012; Gharibi et al., 2013; Potrich et al., 2010).

In a recent scientific study (Dias et al., 2013), wild and commercial samples of $A$. millefolium $\mathrm{L}$. were chemically characterized for their macronutrients, sugars, organic acids, FA and tocopherols. In addition, the in vitro antioxidant properties (free radicals scavenging activity, reducing power and lipid peroxidation inhibition) and the antitumor potential (against breast, lung, cervical and hepatocellular carcinoma cell lines) of their methanolic extracts, infusions and decoctions were evaluated and correlated to the corresponding phenolic profiles. In general, commercial yarrow presented lower $\mathrm{EC}_{50}$ (half-maximal effective concentration) values (higher antioxidant activity). Concerning the extract type, decoctions showed the highest $\mathrm{DPPH}^{\bullet}$ scavenging activity $\left(0.25 \pm 0.01 \mathrm{mg} \mathrm{ml}^{-1}\right), \beta$ carotene bleaching inhibition $\left(0.18 \pm 0.03 \mathrm{mg} \cdot \mathrm{ml}^{-1}\right)$ and TBARS inhibition $\left(0.04 \pm 0.01 \mathrm{mg} \mathrm{ml}^{-1}\right)$, while infusions presented the highest reducing power $\left(0.12 \pm 0.01 \mathrm{mg} \mathrm{ml}^{-1}\right)$ (Dias et al., 2013).

The major antioxidant compounds found in A. millefolium are flavonoids like apigenin and quercetin, and phenolic acids (e.g., caffeoylquinic acid), which are known to act as reducing agents, hydrogen donators or singlet oxygen quenchers against reactive species involved in oxidative stress. The phytochemical profile of $A$. millefolium showed also relevant contents in organic acids (mainly oxalic, quinic, and citric), FA (with linoleic and palmitic acids as the major ones) and tocopherols (specially, $\gamma$-tocopherol)(Benedek et al., 2007; Dias et al., 2013; Gharibi et al., 2013; Vitalini et al., 2011).

\subsection{Acmella oleraceae Murr.}

A. oleraceae Murr. (also known as Spilanthes acmella) is a therapeutically important annual or short-lived perennial medicinal herb with yellow, non-fragrant flowers (Abeysiri et al., 2013). It has been widely used in Ayurveda and folk systems of medicine as an anti-inflammatory, antiseptic and anesthetic drug since historic times. In traditional medicine, flowers have been chewed to relieve toothache and infection of throat and to paralyze the tongue (Dias et al., 2012; Leng et al., 2011).

Biological properties of A. oleraceae mainly depend on $\mathrm{N}$ alkylamides, specially on spilanthol, the principal bioactive compound which showed important bioactivities such as antioxidant, anti-inflammatory, or diuretic activity and oral health care (it has traditionally been used for the treatment of toothache (Boonen et al., 2010). Other important phytochemicals in this species include alkaloids, flavonoids, saponins, steroid glycosides and tannins, which were all detected in the three main parts (leaf, stem and flower) of A. oleraceae. The phenolic contents were significantly higher in leaves and flowers while the lowest value was observed in stems (leaf: $7.59 \pm 1.26$; flower: $5.34 \pm 0.75$; stem: $1.65 \pm 0.35$, results in $\mathrm{mg}$ of gallic acid equivalents $\mathrm{g}^{-1}$ dry matter). The total antioxidant capacity (TAC, in $\mathrm{mg}$ trolox equivalents $\mathrm{g}^{-1}$ dry matter) was also significantly different among leaf $(5.29 \pm 0.85)$, stem $(3.42 \pm 0.59)$ and flower $(1.42 \pm 0.40)$. The reported results represent the scientific validation of the potential use of leaves and flowers in traditional systems of medicine (Abeysiri et al., 2013; Shanthi and Amudha, 2010).

\subsection{Artemisia absinthium $L$.}

A. absinthium L., commonly known as wormwood (Citronelamaior in Portugal) grows as a perennial herb with fibrous roots on non-cultivated, arid ground or rocky slopes and at the edge of footpaths and fields. The plant is recognized by its characteristic odor which makes it useful for making biological sprays against pests. It is used in companion planting to prevent weeds' growing, since its roots secrete substances that inhibit the growth of surrounding plants, besides having repellant activity against insect larvae. It is commonly used as an ingredient in the spirit absinthe, and as a flavoring agent in some other spirits and wines. A. absinthium has been used as herbal medicine throughout Europe, Middle East, North Africa, and Asia. Their health effects include anti-helminthic, choleretic, antiseptic, balsamic, depurative, digestive, diuretic and emmenagogue activities, having also been used in treating leukemia and sclerosis (Canadanovic-Brunet et al., 2005). Recently, the aerial part of $A$. absinthium has shown anti-snake venom activity, while other species of the genus Artemisia exhibited antimalarial and anticancer activities, among other prominent biological effects (Canadanovic-Brunet et al., 2005; Nalbantsoy et al., 2013; Shafi et al., 2012; Sharopov et al., 2012).

Besides the bioactivity evaluation assays, different phytochemicals were also characterized (Bailen et al., 2013; Lee et al., 2013). The phenolic compounds in the wormwood leaves extract were identified and salicylic acid was the dominant phenolic compound $\left(\approx 14400.45 \mu \mathrm{gg}^{-1} \mathrm{DW}\right)$, followed by myricetin $\left(\approx 1086.55 \mu \mathrm{gg}^{-1}\right.$ DW), caffeic acid $\left(\approx 80 \mu g^{-1} \mathrm{DW}\right)$, gallic acid $\left(\approx 64 \mu \mathrm{gg}^{-1} \mathrm{DW}\right)$ and ferulic acid ( $\left.54 \mu \mathrm{gg}^{-1} \mathrm{DW}\right)$. Other detected compounds were quercetin and kaempferol (flavonols), ferulic acid and $o$-coumaric acid (hydroxycinnamic acids), gallic acid, vanillic acid, $\beta$-resorcylic acid and protocatechuic acid (hydroxybenzoic acids). Therefore, the content of total phenolic compounds in the extracts might explain their high antioxidant activities, especially in aqueous extracts, which accounted for the highest antioxidant activity, as evaluated through DPPH ${ }^{\bullet}$ scavenging activity, reducing power and FolinCiocalteu assays (Lee et al., 2013).

\subsection{Bidens pilosa $L$.}

Bidens pilosa, commonly known as "hairy beggar ticks," "sticks tights," and "Spanish needles" is widely distributed in subtropical and tropical regions and presents typical yellow flowers. The plant is used in folk medicine for its anti-inflammatory, antiseptic, liverprotective, anti-hypoglycemic and blood-pressure lowering effects. It has been widely used in Taiwan as a traditional medicine, being also the major ingredient of an herbal infusion that is believed to prevent inflammation and cancer (Dimo et al., 2002; Yang et al., 2006).

The major bioactive components found in Bidens pilosa contributing to its antioxidant activity are phenylpropanoid glucosides, polyacetylenes, diterpenes, flavonoids and flavone glycosides. In addition, forty-four compounds, including the major terpenes $\beta$-caryophyllene $(10.9 \%$ and $5.1 \%$ in the leaves and flowers, respectively) and $\tau$-cadinene $(7.82 \%$ and $6.13 \%$ in the leaves and flowers, respectively) were identified in the yellowish essential oils obtained from its fresh leaves and flowers (Krishnaiah et al., 
2011). These essential oils were reported as having the capacity to reduce the stable free radical $\mathrm{DPPH}^{\bullet}$ to the corresponding diphenylpicrylhydrazine with $\mathrm{IC}_{50}$ values of 57 and $50 \mu \mathrm{g} \mathrm{ml}^{-1}$, respectively, revealing that the flowers of $B$. pilosa have an antioxidant activity that is similar to that of typical synthetic antioxidants (Deba et al., 2008).

\subsection{Carthamus tinctorius $L$.}

In Portugal, Carthamus tinctorius L. (commonly known as safflower) is particularly abundant in the South (Especially in Alentejo province), where it its leaves are used to extract colorants with application in cooking and dyeing machinery, while the seeds are used for cheese manufacture. Regarding its biological activity, C. tinctorius has gradually been investigated due to its medicinal value and health care properties, besides having a wide use in traditional Chinese medicine. In addition, safflower has been used as an herbal medicine in Korea for the promotion of bone formation and in the treatment of osteoporosis and rheumatism. These properties are probably related to the serotonin derivatives, which were identified as the major phenolic constituents of defatted safflower seeds. These compounds have been reported for their strong antioxidant activity and biological effects on plasma and liver lipid status, viability and growth of cancer cell lines or fibroblasts and cellular pro-inflammatory cytokine or melanin production (Bae et al., 2002; Cho et al., 2004). Among the identified derivatives, the serotonin alkaloids (e.g., $N$-feruloylseretonin and $\mathrm{N}$-p-cumaroylserotonin) are potent inhibitors of melanin production suggesting its potential use as inhibitors of melanogenesis. Other phenolic compounds include the quinochalcones responsible for the yellow and red floral pigments and different flavonoid glycosides, which, as widely recognized, are closely related to the antioxidant activity. The quinochalcones and flavonoids, the major antioxidants present in flowers of $C$. tinctorius (aqueous extracts), have been assessed in several studies for their ability to scavenge $\operatorname{ROS}\left(\mathrm{O}_{2}{ }^{\bullet-} \mathrm{HO}^{\bullet},{ }^{1} \mathrm{O}_{2}\right)$ and DPPH${ }^{\bullet}$ (Zhou et al., 2014).

\subsection{Inula crithmoïdes $L$.}

The genus Inula includes more than 100 species, being mainly found in Europe, Africa, and Asia. In some locations, I. crithmoïdes is an important constituent of the human diet. Young leaves are eaten raw or cooked and the fleshy leaves and young shots are pickled and used as a relish in salads. The flowering branches of Inula species are used in traditional medicine for treatment of bronchitis, tuberculosis, anemia, malaria, urinary tract diseases, and also as an astringent (Abdel-Wahhab et al., 2008; Fontana et al., 2014).

The described bioactivity might be related with the high levels of phenolic compounds, characteristic of the Asteraceae family, as those detected in the acetonic extracts of I. crithmoïdes. Regarding its antioxidant activity, this species showed high potential as a $\mathrm{DPPH}^{\bullet}$ scavenger $\left(\mathrm{IC}_{50}=12.8 \mu \mathrm{g} \mathrm{m}^{-1}\right)$ and as a ferric reducing agent $\left(\mathrm{EC}_{50}=0.90 \mathrm{mg} \mathrm{ml}^{-1}\right.$ in the FRAP assay) (Jallali et al., 2014).

\subsection{Matricaria recutita $L$.}

M. recutita $\mathrm{L}$. is an herbaceous plant indigenous to Europe and Western Asia. Several products derived from chamomile are commercially available as soaps, detergents, fragrances, lotions, hair products, baked goods, confectionery, beverages and infusions. The consumption of chamomile' infusions is estimated in more than one million cups per day (Maschi et al., 2008; McKay and Blumberg, 2006).

The main pharmacological effects are determined by the biologically active constituents, which include sesquiterpenic and phenolic compounds. Sesquiterpenic compounds such as $\alpha$ - bisabolol, bisabolol oxides A and B, chamazulene and farnesene, and phenolic compounds (namely apigenin, quercetin, patuletin, and luteolin, and their glucosides, and the coumarins herniarin and umbelliferone), are considered to be the major bioactive compounds of chamomile. Sesquiterpenic compounds are widely found in the essential oils of several plants and fruits, providing a profuse spectrum of aromas, mostly perceived as very pleasant (Barros et al., 2010; Guimarães et al., 2013; McKay and Blumberg, 2006; Salamon, 2007; Srivastava et al., 2010).

Several biological effects have been attributed to $M$. recutita $\mathrm{L}$., such as anti-microbial, antioxidant, anti-malarial, anti-mutagenic, anti-platelet, anti-cancer, anti-inflammatory, anti-genotoxic, antispasmolytic, sedative and hypocholesterolemic. Furthermore, it has interesting gastrointestinal, hepatic and topical properties. Some of its common uses include flatulent nervous dyspepsia, travel sickness, nasal catarrh, restlessness, gastro-intestinal disorders associated with nervous irritability, hemorrhoids, mastitis, leg ulcer, renal colic, nausea, constipation, expulsion of parasitic worms, stomach complaints and skin diseases. The essential oil of chamomile revealed anti-inflammatory, anti-bacterial, antimycotic, and ulcer-protective properties (Guimarães et al., 2013; McKay and Blumberg, 2006; Petronilho et al., 2012). The antioxidant activity of $M$. recutita has been object of several studies, either its whole extracts, or isolated compounds such as chamazulene, nerolidol and $\alpha$-bisabolol, particularly its scavenging activity by $\mathrm{DPPH}^{\bullet}$ and TBARS formation inhibition (Petronilho et al., 2012; Roby et al., 2013).

\subsection{Otanthus maritimus $L$.}

Otanthus maritimus L. is the only species of the monotypic genus Otanthus. This species lives on maritime sands along the coasts of South and West Europe, northwards to South-East Ireland. The use of 0 . maritimus has been reported in traditional medicine, specifically in the treatment of toothache, asthmatic bronchitis, dysentery and bladder inflammation (Cabral et al., 2013; Tsoukatou et al. 2000).

Different studies report the isolation of several components from the aerial parts of 0 . maritimus: flavonoids, sesquiterpene lactones, monoterpenes, lignanes and amides. The roots contain fatty acid amides, acetylene derivatives and sesquiterpenes. Over 30 compounds have been identified in essential oils, with a primary emphasis on chrysanthenone (40.4-57.2\%), filifolone (12.2-15.5\%), cis-chrysantenyl acetate (10.1-11.2\%) and $\alpha$-pinene (6.7-7.2\%) with anti-fungal and anti-inflammatory activity. Chrysanthenone, the main compound of $O$. maritimus essential oil, is a rare bicyclic monoterpene ketone with a slightly oily-floral aroma suitable for aromatic industry, being found only in members of the Asteraceae family (Cabral et al., 2013; Muselli et al., 2007; Ruiu et al., 2013).

\subsection{Parthenium hysterophorus $L$.}

Parthenium hysterophorus, also known as congress grass, is an invasive weed with high dissemination in India, but which can be found all over the world. All parts of the plant are used in traditional medicine as bitter tonic, febrifuge, emmenagogue, antidysenteric and treatment of many infectious and degenerative diseases (Kumar et al., 2013; Reddy et al., 2011).

Recent studies have identified and quantified the major bioactive compounds present in flowers and roots extracts of $P$. hysterophorus: flavonoids, terpenoids, alkaloids and cardiac glycosides. The total phenolic content was also assessed in the same extracts, which showed a high scavenging capacity against $\mathrm{HO}^{\bullet}$ and ability to protect the lipid membrane from peroxidation. Furthermore, $P$. hysterophorus has been reported for its potential to 
neutralize the free radical induced oxidative damage, antibacterial activity and cytotoxic potential (Kumar et al., 2013, 2014).

\section{Conclusion}

The Asteraceae family has a worldwide distribution with high representation in the Portuguese territory. In recent years, the scientific community, food, pharmaceutical and cosmetic industries have shown an increasing interest in the study and application of plants extracts, in the development of new and improved functional, preventive or curative products, especially those dedicated to solve the specific demands of recurrent illnesses. A common underlying mechanism of these ailments is the production (or exacerbation of production) of reactive species in the human body, which is directly or indirectly related to cardiovascular and neurodegenerative, cancer, aging, eye problems, among others. The bioactive compounds produced by plants, such as those belonging to Asteraceae family, and their recurrent use in traditional medicine boosted the development of applied studies to attest their beneficial properties, namely their high bioactivity levels.

Although many Asteraceae species were already studied for different properties, the species with higher relevance are still scarcely studied, justifying further exploration of their potential bioactivity, allowing to improve the knowledge on the use of their extracts for medicine, pharmaceutical, food and cosmetic industry. The work reported herein, highlights the plants with highest potential to be further studied, especially concerning their most relevant bioactive properties and important bioactive compounds that could be purified following top-of-the-art methodologies. The acquired knowledge could be used in extension applications, such as the incorporation of extracts/isolated compounds in different product types, in response to the growing interest of such resources, as well as the importance of contributing to the sustainable development of a country with such an high biodiversity.

\section{Acknowledgments}

João C.M. Barreira is grateful to Fundação para a Ciência e a Tecnologia (FCT) for his post-doctoral research grant (SFRH/BPD/72802/2012), financed by POPH-QREN and subsidized by FSE and MCTES. This work received financial support from the European Union (FEDER funds through COMPETE) and National Funds (FCT) through project Pest-C/EQB/LA0006/2013. The work also received financial support from the European Union (FEDER funds) under the framework of QREN through Project NORTE-070124 FEDER-000069.

\section{References}

Abajo, C., Boffill, M.Á., Campo, J., Méndez, M.Á., González, Y., Mitjans, M., Vinardell, M.P., 2004. In vitro study of the antioxidant and immunomodulatory activity of aqueous infusion of Bidens pilosa. J. Ethnopharmacol. 93, 319-323.

Abdel-Wahhab, M.A., Abdel-Azim, S.H., El-Nekeety, A.A., 2008. Inula crithmoïdes extract protects against ochratoxin A-induced oxidative stress, clastogenic and mutagenic alterations in male rats. Toxicon 52, 566-573.

Abeysiri, G.R.P.I., Dharmadasa, R.M., Abeysinghe, D.C., Samarasinghe, K., 2013. Screening of phytochemical, physico-chemical and bioactivity of differen parts of Acmella oleraceae Murr. (Asteraceae), a natural remedy for toothache. Ind. Crops Prod. 50, 852-856.

Alam, M.N., Bristi, N.J., Rafiquzzaman, M., 2013. Review on in vivo and in vitro methods evaluation of antioxidant activity. Saudi Pharm. J. 21, 143-152.

Albayrak, S., Aksoy, A., Sagdic, O., Hamzaoglu, E., 2010. Compositions, antioxidant and antimicrobial activities of Helichrysum (Asteraceae) species collected from Turkey. Food Chem. 119, 114-122.

Amarowicz, R., Pegg, R.B., Rahimi-Moghaddam, P., Barl, B., Weil, J.A., 2004 Free-radical scavenging capacity and antioxidant activity of selected plant species from the Canadian prairies. Food Chem. 84, 551-562.

Amat, N., Upur, H., Blažeković, B., 2010. In vivo hepatoprotective activity of the aqueous extract of Artemisia absinthium L. against chemically and immunologically induced liver injuries in mice. J. Ethnopharmacol. 131 $478-484$
Antolovich, M., Prenzler, P.D., Patsalides, E., McDonald, S., Robards, K., 2002. Methods for testing antioxidant activity. Analyst 127, 183-198.

Apak, R., Güçlü, K., Özyürek, M., Karademir, S.E., 2004. Novel total antioxidant capacity index for dietary polyphenols and vitamins $C$ and $E$, using their cupric ion reducing capability in the presence of neocuproine: CUPRAC method. J. Agric. Food. Chem. 52, 7970-7981

Badarinath, A.V., Rao, K.M., Chetty, C.M.S., Ramkanth, S., Rajan, T.V.S., Gnanaprakash, K., 2010. A review on in-vitro antioxidant methods: comparisons, correlations and considerations. Int. J. Pharm. Tech. Res. 2, 1276-1285.

Bae, S.-J., Shim, S.-M., Park, Y.-J., Lee, J.-Y., Chang, E.-J., Choi, S.-W., 2002 Cytotoxicity of phenolic compounds isolated from seeds of safflower (Carthamus tinctorius L.) on cancer cell lines. Food Sci. Biotechnol. 11, $140-146$.

Bagh, M.B., Thakurta, I.G., Biswas, M., Behera, P., Chakrabarti, S., 2011. Age-related oxidative decline of mitochondrial functions in rat brain is prevented by long term oral antioxidant supplementation. Biogerontology 12, 119-131.

Bailen, M., Julio, L.F., Diaz, C.E., Sanz, J., Martínez-Díaz, R.A., Cabrera, R., Burillo, J., Gonzalez-Coloma, A., 2013. Chemical composition and biological effects of essential oils from Artemisia absinthium L. cultivated under different environmental conditions. Ind. Crops Prod. 49, 102-107.

Baretta, I.P., Felizardo, R.A., Bimbato, V.F., Santos, M.G.J., Kassuya, C.A.L., Junior, A.G., Silva, C.R., Oliveira, S.M., Ferreira, J., Andreatini, R., 2012. Anxiolytic-like effects of acute and chronic treatment with Achillea millefolium L. extract. J. Ethnopharmacol. 140, 46-54.

Barros, L., Oliveira, S., Carvalho, A.M., Ferreira, I.C.F.R., 2010. In vitro antioxidant properties and characterization in nutrients and phytochemicals of six medicinal plants from the Portuguese folk medicine. Ind. Crops Prod. 32, 572-579.

Benedek, B., Gjoncaj, N., Saukel, J., Kopp, B., 2007. Distribution of phenolic compounds in Middleeuropean taxa of the Achillea millefolium L. aggregate. Chem. Biodivers, 4, 849-857.

Benfeito, S., Oliveira, C., Soares, P., Fernandes, C., Silva, T., Teixeira, J., Borges, F., 2013. Antioxidant therapy: still in search of the magic bullet. Mitochondrion 13, 427-435.

Benzie, I.F.F., Strain, J.J., 1996. The ferric reducing ability of plasma (FRAP) as a measure of antioxidant power: the FRAP assay. Anal. Biochem. 239, 70-76.

Benzie, I.F.F., Strain, J.J., 1999. Ferric reducing antioxidant power assay: direct measure of total antioxidant activity of biological fluids and modified version for simultaneous measurement of total antioxidant power and ascorbic acid concentration. Methods Enzymol. 299, 15-27.

Berger, R.G., Lunkenbein, S., Ströhle, A., Hahn, A., 2012. Antioxidants in food: mere myth or magic medicine? CRC Cr. Rev. Food Sci. 52, 162-171.

Blair, I.A., 2008. DNA adducts with lipid peroxidation products. J. Biol. Chem. 283, $15545-15549$

Boonen, J., Baert, B., Roche, N., Burvenich, C., Spiegeleer, B., 2010. Transdermal behaviour of the $\mathrm{N}$-alkylamide spilanthol (affinin) from Spilanthes acmella, (Compositae) extracts. J. Ethnopharmacol. 127, 77-84.

Bora, K.S., Sharma, A., 2010. Neuroprotective effect of Artemisia absinthium L. on focal ischemia and reperfusion-induced cerebral injury. J. Ethnopharmacol. 129, 403-409

Bouayed, J., Bohn, T., 2010. Exogenous antioxidants-double-edged swords in cellular redox state: health beneficial effects at physiologic doses versus deleterious effects at high doses. Oxid. Med. Cell Longev. 3, 228-237.

Burda, S., Oleszek, W., 2001. Antioxidant and antiradical activities of flavonoids. J Agric. Food Chem. 49, 2774-2779.

Bureau, A., Lahet, J.-J., Lenfant, F., Bouyer, F., Petitjean, M., Chaillot, B., Freysz, M., 2005. Optimization of a model of red blood cells for the study of anti-oxidant drugs, in terms of concentration of oxidant and phosphate buffer. Biomed. Pharmacother. 59, 341-344.

Cabral, C., Cavaleiro, C., Gonçalves, M.J., Cruz, M.T., Lopes, M.C., Salgueiro, L., 2013. Otanthus maritimus (L.) Hoffmanns. \& link as a source of bioactive and fragrant oil. Ind. Crop Prod. 43, 484-489.

Canadanovic-Brunet, J.M., Djilas, S.M., Cetkovic, G.S., Tumbas, V.T., 2005. Free-radical scavenging activity of wormwood (Artemisia absinthium L.) extracts. J. Sci. Food Agric. 85, 265-272.

Candan, F., Unlu, M., Tepe, B., Daferera, D., Polissiou, M., Sökmen, A., Akpulat, H.A 2003. Antioxidant and antimicrobial activity of the essential oil and methanol extracts of Achillea millefolium subsp. millefolium Afan. (Asteraceae). J. Ethnopharmacol. 87, 215-220.

Carocho, M., Ferreira, I.C.F.R., 2013. A review on antioxidants, prooxidants and related controversy: natural and synthetic compounds, screening and analysis methodologies and future perspectives. Food Chem. Toxicol. 51, 15-25.

Chandrashekhar, V.M., Halagali, K.S., Nidavani, R.B., Shalavadi, M.H., Biradar, B.S., Biswas, D., Muchchandi, I.S., 2011. Anti-allergic activity of German chamomile (Matricaria recutita L.) in mast cell mediated allergy model. J. Ethnopharmacol. $137,336-340$.

Chandrashekhar, V.M., Ranpariya, V.L., Ganapaty, S., Parashar, A., Muchandi, A.A., 2010. Neuroprotective activity of Matricaria recutita L. against global model of ischemia in rats. J. Ethnopharmacol. 127, 645-651.

Chetan, J., Kumara, K.K.S., Sekhar, S., Prakash, H.S., 2012. Antioxidant, antibacterial and DNA protecting activity of selected medicinally important Asteraceae plants. Int. J. Pharm. Pharm. Sci. 4, 257-261.

Chicaro, P., Pinto, E., Colepicolo, P., Lopes, J.L.C., Lopes, N.P., 2004. Flavonoids from Lychnophora passerina (Asteraceae): potential antioxidants and UV-protectants. Biochem. Syst. Ecol. 32, 239-243. 
Chien, S.-C., Young, P.H., Hsu, Y.-J., Chen, C.-H., Tien, Y.-J., Shiu, S.-Y., Li, T.-H., Yang, C.-W., Marimuthu, P., Tsai, L.F.-L., Yang, W.-C., 2009. Anti-diabetic properties of three common Bidens pilosa variants in Taiwan. Phytochemistry 70, $1246-1254$.

Cho, S.-H., Lee, H.-R., Kim, T.-B., Choi, S.-W., Lee, W.-J., Choi, Y., 2004. Effects of defatted safflower seed extract and phenolic compounds in diet on plasma and liver lipid in ovariectomized rats fed high-cholesterol diets. J. Nutr. Sci. Vitaminol. 50, 32-37.

Dai, F., Miao, Q., Zhou, B., Yang, L., Liu, Z.-L., 2006. Protective effects of flavonols and their glycosides against free radical-induced oxidative hemolysis of red blood cells. Life Sci. 78, 2488-2493.

Das, B., Reddy, V.S., Krishnaiah, M., Sharma, A.V.S., Kumar, K.R., Rao, J.V., Sridhar, V., 2007. Acetylated pseudoguaianolides from Parthenium hysterophorus and their cytotoxic activity. Phytochemistry 68, 2029-2034.

Dasari, S., Wudayagiri, R., Valluru, L., 2013. Efficacy of treatment on antioxidant status in cervical cancer patients: a case control study. Free Rad. Antiox. 3, $87-92$.

Dasgupta, N., De, B., 2007. Antioxidant activity of some leafy vegetables of India: comparative study. Food Chem. 101, 471-474.

Deba, F., Xuan, T.D., Yasuda, M., Tawata, S., 2008. Chemical composition and antioxidant, antibacterial and antifungal activities of the essential oils from Bidens pilosa L. var. Radiata. Food Control 19, 346-352.

Dall'Acqua, S., Bolego, C., Cignarella, A., Gaion, R.M., Innocenti, G., 2011. Vasoprotective activity of standardized Achillea millefolium extract. Phytomedicine 18, 1031-1036.

Denni, M., Mammen, D., 2012. A critical evaluation on the reliability of two aluminum chloride chelation methods for quantification of flavonoids. Food Chem. 135, 1365-1368.

Dewan, S.M.R., Amin, M.N., Adnan, T., UdDin, S.M.U., Shahid-Ud-Daula, A.F.M., Sarwar, G., Hossain, M.S., 2013. Investigation of analgesic potential and in vitro antioxidant activity of two plants of Asteraceae family growing in Bangladesh. J. Pharm. Res. 6, 599-603.

Dias, A.M.A., Santos, P., Seabra, I.J., Júnior, R.N.C., Braga, M.E.M., De Sousa, H.C., 2012. Spilanthol from Spilanthes acmella, flowers, leaves and stems obtained by selective supercritical carbon dioxide extraction. J. Supercrit. Fluid 61, 62-70.

Dias, M.I., Barros, L., Alves, R.C., Oliveira, M.B.P.P., Santos-Buelga, C., Ferreira, I.C.F.R., 2014. Nutritional composition, antioxidant activity and phenolic compounds of wild Taraxacum sect. Ruderalia. Food Res. Int 56, 266-271.

Dias, M.I., Barros, L., Dueñas, M., Pereira, E., Carvalho, A.M., Alves, R.C., Oliveira, M.B.P.P., Santos-Buelga, C., Ferreira, I.C.F.R., 2013. Chemical composition of wild and commercial Achillea millefolium L. and bioactivity of the methanolic extract, infusion and decoction. Food Chem. 141, 4152-4160.

Dimo, T., Rakotonirina, S.V., Tan, P.V., Azay, J., Dongo, E., Cros, G., 2002. Leaf methanol extract of Bidens pilosa prevents and attenuates the hypertension induced by high-fructose diet in Wistar rats. J. Ethnopharmacol. 83, $183-191$.

Ďuračková, Z., 2010. Some current insights into oxidative stress. Physiol. Res. 59, 459-469.

Fernández, J., Perez-Alvarez, J.A., Fernández-Lopez, J.A., 1997. Thiobarbituric acid test for monitoring lipid oxidation in meat. Food Chem 59, 345-353.

Flora, S.J.S., 2009. Structural, chemical and biological aspects of antioxidants for strategies against metal and mettaloid exposure. Oxidative Med. Cell Longev. 2, 191-206.

Fontana, G., Bruno, M., Senatore, F., Formisano, C., 2014. Volatile constituents of aerial parts of two Mediterranean species of Inula: Inula crithmoides L. and I. verbascifolia (Willd.) Hausskn. (Asteraceae). Nat. Prod. Res. 28, 984-993.

Frankel, E.N., Meyer, A.S., 2000. The problems of using one dimensional methods to evaluate multifunctional food and biological antioxidants. J. Sci. Food Agric. 80, 1925-1941.

Gharibi, S., Tabatabaei, B.E.S., Saeidi, G., Golic, S.A.H., Talebi, M., 2013. Total phenolic content and antioxidant activity of three Iranian endemic Achillea species. Ind. Crop. Prod. 50, 154-158.

Giles, G.I., Tasker, K.M., Jacob, C., 2001. Hypothesis: the role of reactive sulfur species in oxidative stress. Free Radical Biol. Med. 31, 1279-1283.

Gonzalez-Coloma, A., Bailen, M., Diaz, C.E., Fraga, B.M., Martínez-Díaz, R., Zuñiga, G.E., Contreras, R.A., Cabrera, R., Burillo, J., 2012. Major components of Spanish cultivated Artemisia absinthium populations: antifeedant, antiparasitic, and antioxidant effects. Ind. Crops Prod. 37, 401-407.

Guimarães, R., Barros, L., Dueñas, M., Calhelha, R.C., Carvalho, A.M., Santos-Buelga C., Queiroz, M.J.R.P., Ferreira, I.C.F.R., 2013. Nutrients, phytochemicals and bioactivity of wild Roman chamomile: a comparison between the herb and its preparations. Food Chem. 136, 718-725.

Güngör, N., Özyürek, M., Güçlü, K., Çekic, S.D., Apak, R., 2011. Comparative evaluation of antioxidant capacities of thiol-based antioxidants measured by different in vitro methods. Talanta 83, 1650-1658.

Harborne, J.B., Williams, C.A., 2000. Advances in flavonoid research since 1992. Phytochemistry 55, 481-504.

Hernandez-Montes, E., Pollard, S.E., Vauzour, D., Jofre-Montseny, L., Rota, C., Rimbach, G., Weinberg, P.D., Spencer, J.P.E., 2006. Activation of glutathione peroxidase via Nrf1 mediates genistein's protection against oxidative endothelial cell injury. Biochem. Bioph. Res. Co. 346, 851-859.

Hsu, Y.-J., Lee, T.-H., Chang, C.L.-T., Huang, Y.-T., Yang, W.-C., 2009. Anti-hyperglycemic effects and mechanism of Bidens pilosa water extract. J. Ethnopharmacol. 122, 379-383.

Huang, D., Ou, B., Prior, R.L., 2005. The chemistry behind antioxidant capacity assays. J. Agr. Food. Chem. 53, 1841-1856.
Jallali, I., Zaouali, Y., Missaoui, I., Smeoui, A., Abdelly, C., Ksouri, R., 2014. Variability of antioxidant and antibacterial effects of essential oils and acetonic extracts of two edible halophytes: Crithmum maritimum L. and Inula crithmoïdes L. Food Chem 145, 1031-1038.

Jamalian, A., Shams-Ghahfarokhi, M., Jaimand, K., Pashootan, N., Amani, A., Razzaghi-Abyaneh, M., 2012. Chemical composition and antifungal activity of Matricaria recutita flower essential oil against medically important dermatophytes and soil-borne pathogens. J. Med. Mycol. 22, 308-315.

Jayasena, T., Poljak, A., Smythe, G., Braidy, N., Münch, G., Sachdev, P., 2013. The role of polyphenols in the modulation of sirtuins and other pathways involved in Alzheimer's disease. Ageing Res. Rev. 12, 867-883.

Karadag, A., Ozcelik, B., Saner, S., 2009. Review of methods to determine antioxidant capacities. Food Anal. Method 2, 41-60.

Kenny, O., Smyth, T.J., Walsh, D., Kelleher, C.T., Hewage, C.M., Brunton, N.P., 2014 Investigating the potential of under-utilised plants from the Asteraceae family as a source of natural antimicrobial and antioxidant extracts. Food Chem. 161, $79-86$.

Koshland Jr., D.E., 1992. The molecule of the year. Science 258, 1861

Krishnaiah, D., Sarbatly, R., Nithyanandam, R., 2011. A review of the antioxidant potential of medicinal plant species. Food Bioprod. Process 89, 217-233.

Krishnaveni, M., 2013. Air pollution tolerance index and antioxidant activity of Parthenium hysterophorus. J. Pharm. Res. 7, 296-298.

Kumar, S., Mishra, A., Pandey, A.K., 2013. Antioxidant mediated protective effect of Parthenium hysterophorus against oxidative damage using in vitro models. BMC Complement. Alt. Med. 13, 120.

Kumar, S., Pandey, S., Pandey, A.K., 2014. In vitro antibacterial, antioxidant, and cytotoxic activities of Parthenium hysterophorus and characterization of extracts by LC-MS analysis. BioMed. Res. Int. 2014, 10, 495154.

Kunchandy, E., Rao, M.N.A., 1990. Oxygen radical scavenging activity of curcumin. Int. J. Pharm. 58, 237-240.

Kviecinski, M.R., Felipe, K.B., Schoenfelder, T., Wiese, L.P.L., Rossi, M.H., Gonçalez, E., Felicio, J.D., Filho, D.W., Pedrosa, R.C., 2008. Study of the antitumor potential of Bidens pilosa (Asteraceae) used in Brazilian folk medicine. J. Ethnopharmacol. 117, 69-75.

Laguerre, M., Lecomte, J., Villeneuve, P., 2007. Evaluation of the ability of antioxidants to counteract lipid oxidation: existing methods, new trends and challenges. Prog. Lipid. Res. 46, 244-282.

Lee, Y.J., Thiruvengadam, M., Chung, I.M., Nagella, P., 2013. Polyphenol composition and antioxidant activity from the vegetable plant Artemisia absinthium L. Aust. J. Crop Sci. 7, 1921-1926.

Leng, T.C., Ping, N.S., Lim, B.P., Keng, C.L., 2011. Detection of bioactive compounds from Spilanthes acmella (L.) plants and its various in vitro culture products. J. Med. Plant Res. 5, 371-378.

López-Alarcón, C., Denicola, A., 2013. Evaluating the antoxidant capacity of natural products: a review on chemical and cellular-based assays. Anal. Chim. Acta 763, 1-10.

MacDonald-Wicks, L.K., Wood, L.G., Garg, M.L., 2006. Methodology for the determination of biological antioxidant capacity in vitro: a review. J. Sci. Food Agric. 86, 2046-2056.

Magalhães, L.M., Marcela, A.S., Reis, S., Lima, J.L.F.C., 2008. Methodological aspects about in vitro evaluation of antioxidant properties. Anal. Chim. Acta 613 (1), $1-19$.

Maksimović, Z., 2008. In vitro antioxidant activity of ragweed (Ambrosia artemisiifolia L., Asteraceae) herb. Ind. Crops Prod. 28, 356-360.

Martins, N., Ferreira, I.C.F.R., Barros, L., Carvalho, A.M., Henriques, M., Silva, S., 2015. Plants used in folk medicine: the potential of their hydromethanolic extracts against Candida species. Ind. Crops Prod. 66, 62-67.

Maschi, O., Cero, E.D., Galli, G.V., Caruso, D., Bosisio, E., Dell'Agli, M., 2008. Inhibiton of human cAMP-phosphodiesterase as a mechanism of spasmolytic effect of Matricaria recutita L. J. Agr. Food. Chem. 56, 5015-5020.

McKay, D.L., Blumberg, J.B., 2006. A review of the bioactive and potential health benefits of chamomile tea (Matricaria recutita L.). Phytother. Res. 20, 519-530.

Meyer, A.S., Isaksen, A., 1995. Application of enzymes as food antioxidants. Trends Food Sci. Technol. 6, 300-304

Milbury, P., Chen, C.-Y., Dolnikowski, G.G., Blumberg, J.B., 2006. Determination of flavonoids and phenolics and their distribution in almonds. J. Agric. Food. Chem. 54, 5027-5033.

Moon, J.K., Shibamoto, T., 2009. Antioxidant assays for plant and food components. J. Agric. Food. Chem. 57, 1655-1666.

Muselli, A., Rossi, P.G., Desjobert, J.M., Bernardini, A.F., Berti, L., Costa, J., 2007. Chemical composition and antibacterial activity of Otanthus maritimus (L.) Hoffmanns. \& link essential oils from Corsica. Flavour Frag. J. 22, 217-223.

Nalbantsoy, A., Erel, S.B., Köksal, Ç., Göçmen, B., Yıldız, M.Z., Yavaşoğlu, N.Ü.K., 2013. Viper venom induced inflammation with Montivipera xanthina (Gray, 1849) and theanti-snake venom activities of Artemisia absinthium L. in rat. Toxicon 65, 34-40.

Ng, T.B., Liu, F., Wang, Z., 2000. Antioxidative activity of natural products from plants. Life Sci. 66, 709-723.

Niki, E., 2010. Assessment of antioxidant capacity in vitro and in vivo. Free Radical Biol. Med. 49, 503-515.

Niki, E., Komuro, E., Takahashi, M., Urano, S., Ito, E., Terao, K., 1988. Oxidative hemolysis of erythrocytes and its inhibition by free radical scavengers. J. Biol. Chem. 263, 19809-19814

Njenga, E.W., Viljoen, A.M., 2006. In vitro 5-lipoxygenase inhibition and anti-oxidant activity of Eriocephalus L. (Asteraceae) species. S. Afr. J. Bot. 72, 637-641. 
Oliveira, F.Q., Andrade-Neto, V., Krettli, A.U., Brandão, M.G.L., 2004. New evidences of antimalarial activity of Bidens pilosa roots extract correlated with polyacetylene and flavonoids. J. Ethnopharmacol. 93, 39-42.

Omezzine, F., Ladhari, A., Rinez, A., Haouala, R., 2011. Potent herbicidal activity of Inula crithmoïdes L. Sci. Hortic. 130, 853-861.

Ordoñez, A.A.L., Gomez, J.D., Vattuone, M.A., Isla, M.I., 2006. Antioxidant activities of Sechium edule (Jacq.) Swartz extracts. Food Chem. 97, 452-458.

Pacher, P., Beckman, J.S., Liaudet, L., 2007. Nitric oxide and peroxynitrite in health and disease. Physiol. Rev. 87, 315-424.

Panda, S.K., 2012. Assay guided comparison for enzymatic and non-enzymatic antioxidant activities with special reference to medicinal plants. In: El-Missiry, M.A. (Ed.), Antioxidant Enzyme. InTech, http://dx.doi.org/10.5772/50782

Pereira, R.L.C., Ibrahim, T., Lucchetti, L., Silva, A.J.R., Moraes, V.L.G., 1999. Immunosuppressive and anti-inflammatory effects of methanolic extract and the polyacetylene isolated from Bidens pilosa L. Immunopharmacology 43, 31-37.

Petronilho, S., Maraschin, M., Coimbra, M.A., Rocha, S.M., 2012. In vitro and in vivo studies of natural products: a challenge for their valuation. The case study of chamomile (Matricaria recutita L.). Ind. Crops Prod. 40, 1-12.

Phillipson, J.D., 2007. Phytochemistry and pharmacognosy. Review. Phytochemistry 68, 2960-2972.

Potrich, F.B., Allemand, A., Silva, L.M., Santos, A.C., Baggio, C.H., Freitas, C.S., Mendes, D.A.G.B., Andre, E., Werner, M.F.P., Marques, M.C.A., 2010. Antiulcerogenic activity of hydroalcoholic extract of Achillea millefolium L. involvement of the antioxidant system. J. Ethnopharmacol. 130, 85-92.

Prior, R.L., Hoang, H., Gu, L., Wu, X., Bacchiocca, M., Howard, L., Woodill, M.H., Huang, D., Ou, B., Jacob, R., 2003. Assays for hydrophilic and lipophilic antioxidant capacity (oxygen radical absorbance capacity (ORAC (FL)) of plasma and other biological and food samples. J. Agric. Food Chem. 51, 3273-3279.

Prior, R.L., Wu, X., Schaich, K., 2005. Standardized methods for the determination of antioxidant capacity of phenolics in foods and dietary supplements. J. Agric. Food Chem. 53, 4290-4302.

Rajiv, P., Rajeshwari, S., Venckatesh, R., 2013. Bio-Fabrication of zinc oxide nanoparticles using leaf extract of Parthenium hysterophorus L. and its size-dependent antifungal activity against plant fungal pathogens. Spectrochim. Acta A 112, 384-387.

Ravishankar, D., Rajora, A.K., Greco, F., Osborn, H.M.I., 2013. Flavonoids as prospective compounds for anti-cancer therapy. Int. J. Biochem. Cell Biol. 45 2821-2831.

Reddy, D.M., Qazi, N.A., Sawant, S.D., Bandey, A.H., Srinivas, J., Shankar, M., Singh, S.K., Verma, M., Chashoo, G., Saxena, A., Mondhe, D., Saxena, A.K., Sethi, V.K. Taneja, S.C., Qazi, G.N., Kumar, H.M.S., 2011. Design and synthesis of spiro derivatives of parthenin as novel anticancer agents. Eur. J. Med. Chem. 46, 3210-3217.

Robak, J., Gryglewski, R.J., 1988. Flavonoids are scavengers of superoxide anions. Biochem. Pharmacol. 37, 837-841.

Robards, K., Antolovich, M., 1997. Analytical chemistry of fruit bioflavonoids. A review. Anal. 122, 11R-34R.

Roby, M.H.H., Sarhan, M.A., Selim, K.A.H., Khalel, I.K., 2013. Antioxidant and antimicrobial activities of essential oil and extracts of fennel (Foeniculum vulgare L.) and chamomile (Matricaria chamomilla L.). Ind. Crops Prod. 44, 437-445.

Rozpądek, P., Wężowicz, K., Stojakowska, A., Malarz, J., Surówka, E., Sobczyk, Ł., Anielska, T., Ważny, R., Miszalski, Z., Turnau, K., 2014. Mycorrhizal fungi modulate phytochemical production and antioxidant activity of Cichorium intybus Ł. (Asteraceae) under metal toxicity. Chemosphere 112, 217-224.

Ruch, R.J., Cheng, S.J., Klaunig, J.E., 1989. Prevention of cytotoxicity and inhibition of intercellular communication by antioxidant catechins isolated from Chinese green tea. Carcinogenesis 10, 1003-1008.

Ruiu, S., Anzani, N., Orrù, A., Floris, C., Caboni, P., Maccioni, E., Distinto, S., Alcaro, S., Cottiglia, F., 2013. N-Alkyl dien- and trienamides from the roots of Otanthus maritimus with binding affinity for opioid and cannabinoid receptors. Bioorgan. Med. Chem. 21, 7074-7082.
Salamon, I., 2007. Effect of the internal and external factors on yield and qualitative-quantitative characteristics of chamomile essential oil. Acta Hortic. 749, 45-64.

Sebai, H., Jabri, M.-A., Souli, A., Rtibi, K., Selmi, S., Tebourbi, O., El-Benna, J., Sakly, M., 2014. Antidiarrheal and antioxidant activities of chamomile (Matricaria recutita L.) decoction extract in rats. J. Ethnopharmacol. 152, 327-332.

Shafi, G., Hasan, T.N., Syed, N.A., Al-Hazzani, A.A., Alshatwi, A.A., Jyothi, A., Mun-shi, A., 2012. Artemisia absinthium (AA): a novel potential complementary and alternative medicine for breast cancer. Mol. Biol. Rep. 39, 7373-7379.

Shahat, A.A., Ibrahim, A.Y., Elsaid, M.S., 2014. Polyphenolic content and antioxidant activity of some wild Saudi Arabian asteraceae plants. Asian Pac. J. Trop. Med. 7, 545-551.

Shanthi, P., Amudha, P., 2010. Evaluation of the phytochemical constituents of Acmella calva (DC.) R. K. Jansen. Int. J. Pharm. Bio. Sci. 1, 308-314.

Sharma, O.P., Bhat, T.K., 2009. DPPH• antioxidant assay revisited. Food Chem. 113, 1202-1205.

Sharopov, F.S., Sulaimonova, V.A., Setzer, W.N., 2012. Composition of the essential oil of Artemisia absinthium from Tajikistan. Rec. Nat. Prod. 6, 127-134

Souza, P., Gasparotto, J., r, A., Crestani, S., Stefanello, M.É.A., Marques, M.C.A., Silva-Santos, J.E., Kassuya, C.A.L., 2011. Hypotensive mechanism of the extracts and artemetin isolated from Achillea millefolium L. (Asteraceae) in rats. Phytomedicine 18, 819-825.

Srivastava, J.K., Shankar, E., Gupta, S., 2010. Chamomile: a herbal medicine of the past with bright future. Mol. Med. Rep. 3, 895-901.

Tariq, K.A., Chishti, M.Z., Ahmad, F., Shawl, A.S., 2009. Anthelmintic activity of extracts of Artemisia absinthium against ovine nematodes. Vet. Parasitol. 160, 83-88.

Tennyson, S., Balaraju, K., Park, K., Ravindran, K.J., Eapen, A., William, S.J., 2012. In vitro antioxidant activity of Ageratum houstonianum Mill. (Asteraceae). Asian Pac. J. Trop. Med. 2, S712-S714.

Toyang, N.J., Verpoorte, R., 2013. A review of the medicinal potentials of plants of the genus Vernonia (Asteraceae). J. Ethnopharmacol. 146, 681-723.

Trumbeckaite, S., Benetis, R., Bumblauskiene, L., Burdulis, D., Janulis, V., Toleikis, A. Viškelis, P., Jakštas, V., 2011. Achillea millefolium L. s. l. herb extract: antioxidant activity and effect on the rat heart mitochondrial functions. Food Chem. 127, 1540-1548.

Tsoukatou, M., Vagias, C., Harvala, C., Roussis, V., 2000. Essential oil and headspace analysis of the maritime Bombycilaena erecta and Otanthus maritimus species growing wild in Greece. J. Essent. Oil Res. 12, 360-364.

UdDin, I., Bano, A., Masood, S., 2015. Chromium toxicity tolerance of Solanum nigrum L. and Parthenium hysterophorus L. plants with reference to ion pattern, antioxidation activity and root exudation. Ecotox. Environ. Saf. 113, 271-278.

Vitalini, S., Beretta, G., Iriti, M., Orsenigo, S., Basilico, N., Dall'Acqua, S., Iorizzi, M., Fico, G., 2011. Phenolic compounds from Achillea millefolium L. and their bioactivity. Acta Biochim. Pol. 58, 203-212.

Yang, H.-L., Chen, S.-C., Chang, N.-W., Chang, J--M., Lee, M.-L., Tsai, P.-C., Fu, H.-H. Kao, W.-W., Chiang, H.-C., Wang, H.-H., Hseu, Y.-C., 2006. Protection from oxidative damage using Bidens pilosa extracts in normal human erythrocytes. Food Chem. Toxicol. 44, 1513-1521.

Zhishen, J., Mengcheng, T., Jianming, W., 1999. The determination of flavonoid contents in mulberry and their scavenging effects on superoxide radicals. Food Chem. 64, 555-559.

Zhou, X, Tang, L, Xu, Y, Zhou, G, Wang Z, 2014. Towards a better understanding of medicinal uses of Carthamus tinctorius L. in traditional Chinese medicine: a phytochemical and pharmacological review. J. Ethnopharmacol. 151, 27-43.

Zhu, Q.Y., Holt, R.R., Lazarus, S.A., Orozco, T.J., Keen, C.L., 2002. Inhibitory effects of cocoa flavanols and procyanidin oligomers on free radical-induced erythrocyte hemolysis. Exp. Biol. Med. 227, 321-329. 